\title{
Taxanes in the elderly patient with metastatic breast cancer
}

\author{
This article was published in the following Dove Press journal: \\ Breast Cancer: Targets and Therapy \\ 3 September 2015 \\ Number of times this article has been viewed
}

\section{Denise A Yardley}

Sarah Cannon Research Institute, Nashville, TN, USA
Correspondence: Denise A Yardley Sarah Cannon Research Institute, 250 25th Avenue North, Suite 100, Nashville, TN 37203, USA

Tel +l 6I53297272

Email dyardley@tnonc.com
Abstract: More than $40 \%$ of all breast cancer cases are diagnosed in patients aged $\geq 65$ years, accounting for an ever-increasing disease burden in the elderly. Historically, however, this growing population of breast cancer patients has been underrepresented in clinical trials, resulting in a paucity of data that clinicians can reference in making treatment decisions for their older patients. A consequence may be the undertreatment of elderly patients, who have the highest incidence of breast cancer. However, subgroup analyses of elderly patients in multiple early-Phase (I or II) studies and a handful of small studies with elderly-specific populations have suggested that older patients may experience similar benefit from cancer therapy as younger patients with otherwise similar baseline characteristics. Although steps should be taken to avoid undertreating older patients, a balance must be achieved to avoid overtreatment. Guidelines have been released detailing recommendations for the treatment of elderly breast cancer patients, including a discussion of various geriatric assessments that might aid physicians in selecting patients appropriate for recommended treatment options. Chemotherapy remains a key component of treatment regimens for many older patients. However, the benefit of some agents may be limited by tolerability issues. Taxanes, one of the most established classes of chemotherapy for breast cancer, are known to be highly active and efficacious and to have well-characterized safety profiles. This review discusses factors that influence treatment choices for elderly patients with metastatic breast cancer, and then focuses on clinical data for taxanes in this patient population.

Keywords: breast cancer, elderly, taxane, chemotherapy, treatment guidelines

\section{Introduction}

The term elderly can be defined both chronologically and functionally. Although the chronological definition of elderly has shown considerable variability in the literature, it is clear that older women represent an important and growing population of breast cancer patients. Indeed, more than $40 \%$ of new breast cancer cases are diagnosed in women aged $\geq 65$ years, ${ }^{1}$ with $20 \%$ of new cases per year in the United States diagnosed in women aged $\geq 75$ years. $^{2}$ Breast cancer-specific mortality between 1998 and 2010 in the United States decreased by $1.9 \%$ per year. However, the decreases in mortality between 1990 and 2007 were not shared evenly across age groups. While patients aged 20-49 years experienced a decrease in breast cancer-specific mortality of $2.5 \%$ per year, patients aged 65-74 years experienced a 2.0\% decrease per year, and those aged $\geq 75$ years had only a $1.1 \%$ decrease per year. Elderly patients with breast cancer are known to be undertreated, ${ }^{2,3}$ and this may explain why older patients have benefited less from treatment advances over the past 2 decades. 
There is a lack of strong evidence (level 1) for physicians to consider in making decisions regarding treatment of the elderly. ${ }^{4}$ Therefore, treatment of the elderly is based largely on retrospective subset analyses and extrapolation of results from younger patient populations. Noting the issues of undertreatment and underrepresentation in clinical trials, the International Society of Geriatric Oncology (SIOG) assembled a task force to make evidence-based recommendations for the treatment of breast cancer in elderly patients. ${ }^{4}$ One of the key conclusions the task force reached was that age alone should not dictate therapy. The task force also highlighted the importance of balancing overtreatment and undertreatment of advanced disease in elderly patients, a setting in which the maintenance of quality of life as well as independence is particularly important. Clinicians are increasingly challenged to balance patient comorbidities, social support, cognitive function, and family dynamics in proposing treatment recommendations.

\section{Key issues with elderly patients}

The management of breast cancer in elderly patients depends critically on certain physiological changes that occur with age. ${ }^{5}$ Such changes can affect drug metabolism and distribution. For example, both hepatic mass and the level of cytochrome p450 in the liver decrease with age. ${ }^{5}$ Rates of renal clearance also decrease with age, affecting drug excretion. ${ }^{6,7}$ In addition, increases in body fat and decreases in total body water, which are both associated with aging, may modify the volume of distribution of drugs in the circulation. ${ }^{6}$ All of these factors affect the way drugs are processed in the body and may account for some of the increased toxicity in elderly patients.

A retrospective study evaluated nine Phase I clinical trials to examine whether elderly patients exhibited decreased clearance of experimental drugs. ${ }^{8}$ The results of this study suggested no difference in clearance in older patients compared with their younger counterparts, and the proportion of patients who received at or above the maximum-tolerated dose was similar in patients older or younger than age 65 . Because these data are derived from a small cohort of patients (81 patients $>65$ years of age and 263 patients $\leq 65$ years of age), the generalizability of these results to the population as a whole is limited.

The course and phenotypes of breast cancers that develop in elderly patients differ from those that develop in younger patients. Whether older patients present with a similar degree of tumor burden as younger patients at diagnosis is unclear. ${ }^{49}$ However, it is known that tumors that develop in older patients tend to manifest a different biology, which is less aggressive than that of tumors that develop in younger patients. ${ }^{2,9}$ This is evident in the differences in pathological features. For example, breast tumors in older patients are much more likely to be hormone receptor positive (HR+) and less likely to overexpress human epidermal growth factor receptor 2 (HER2). ${ }^{10}$

In addition to the physiological and pathological factors just described, a number of additional important clinical features may complicate the treatment of breast cancer in the elderly, such as shortened life expectancy, potentially lower performance status, polypharmacy, and numerous chronic and acute comorbidities that not only affect the patient's functional status but also lead to challenges in overlapping toxicities. Logically, as age increases, the risk of dying from noncancer-related causes also increases. While this is often not the immediate focus, oncologists must carefully consider age and the impact of comorbidities versus the predicted benefit of treatment when determining how aggressively to treat patients. ${ }^{11,12}$ Furthermore, therapeutic agents bearing a known toxicity risk that is affected by some other condition may be contraindicated. For example, an oncologist prescribing treatment for a patient with breast cancer who has cardiovascular disease must weigh the risk of cardiotoxicity associated with anthracyclines or trastuzumab against their potential benefits..$^{13-15}$

The issue of polypharmacy is also critical to consider, especially in older patients who are more likely to be receiving treatment for comorbid conditions. Drug-drug interactions can affect pharmacodynamics, absorption, excretion, distribution, and metabolism of systemic therapies, making the relative exposures of drugs less predictable. ${ }^{4,16}$

This review will focus primarily on advanced disease, but many of the conclusions regarding the evaluation of treatment of elderly patients are also relevant in earlier disease settings focused on curative outcomes.

\section{Treatment options}

In a retrospective analysis of five metastatic breast cancer trials conducted by the Piedmont Oncology Association, older patients $(n=70)$ demonstrated similar efficacy from systemic chemotherapy compared with their younger counterparts $(n=60$, aged $50-69$ years and $n=40$, aged $<50$ years) in terms of overall response rate (ORR), time to progression, and overall survival (OS).${ }^{17}$ Notably, the rates of toxic effects were similar between younger 
and older patients. Thus, it appears that the benefits of chemotherapy that apply to younger patients also apply to at least a subset of older patients. This may pertain only to fit elderly patients, with less-fit patients requiring different treatment strategies. ${ }^{18}$

Regardless of patient age, physicians should first establish whether patients are candidates for therapy targeted to HER2 or HRs. ${ }^{18}$ Trastuzumab and pertuzumab, monoclonal antibodies against HER2, ${ }^{19}$ are recommended for many patients with HER2-positive (HER2+) disease; specifically, the combination of trastuzumab, pertuzumab, and a taxane is listed as a preferred first-line treatment regimen for HER2+ metastatic breast cancer. ${ }^{18}$

For patients with HR+ metastatic breast cancer, treatment guidelines from the National Comprehensive Cancer Network (NCCN) recommend endocrine therapy for first-line treatment. ${ }^{18}$ Unfortunately, however, over time many such tumors become refractory to endocrine therapy; such patients may become candidates for cytotoxic chemotherapy. ${ }^{18}$

According to the updated SIOG guidelines, chemotherapy is indicated for elderly patients with metastatic breast cancer that is estrogen-receptor negative or hormone therapy refractory or manifests rapidly progressing tumor burden. ${ }^{4}$ Choosing the appropriate chemotherapy option for elderly patients requires consideration of several variables, including not only antitumor activity, but also factors such as the patient's renal function and the agent's safety profile. ${ }^{4}$ As mentioned previously, renal function may decline with age, and the physician must evaluate whether a therapy that is known to be metabolized renally, such as capecitabine, is appropriate for patients with declining or unpredictable kidney function. ${ }^{6,7,20}$ Agents such as anthracyclines and taxanes are not excreted primarily in the urine $^{21-24}$ and can be considered even for patients with renal impairment. According to treatment guidelines published by the NCCN (not age specific), combination therapy for metastatic disease is not superior to sequential single-agent therapy because of a lack of superior OS. ${ }^{18}$ The SIOG guidelines for elderly patients recommend single-agent chemotherapy regimens over combination chemotherapy for metastatic disease because of the lower degree of toxicity, typically associated with single-agent therapy. ${ }^{4}$ The SIOG guidelines go on to suggest that "preference should be given to chemotherapy agents with better safety profiles (such as weekly taxanes, pegylated liposomal doxorubicin, capecitabine, and vinorelbine) that have been studied in older patients."

\section{Taxanes for the treatment of elderly patients with metastatic breast cancer \\ Taxane development}

The development of taxanes for cancer treatment began after the discovery of paclitaxel, a compound isolated from the bark of the western yew tree, which demonstrated antitumor activity by inhibiting microtubule dynamics in cancer cells. ${ }^{23,25-27}$ This was followed by the development of the molecularly similar compound docetaxel. ${ }^{21}$ Both compounds have demonstrated efficacy in metastatic breast cancer, ${ }^{21,23}$ and the recognition that taxanes, along with anthracyclines, are among the most active classes of drugs for metastatic breast cancer led to their widespread use for advanced disease and subsequent adoption in early-stage breast cancer. ${ }^{18,28}$ Current treatment guidelines recommend taxanes for metastatic and early-stage breast cancer, either as single agents or combined with novel biologic agents; ${ }^{18}$ however, tolerability issues with these drugs and the solvents used to administer them have led to the development of other taxane formulations, including albumin-bound paclitaxel (nab-paclitaxel). ${ }^{29,30}$ The remainder of this review will focus on the efficacy and tolerability of taxanes for the treatment of elderly patients with metastatic breast cancer.

\section{Solvent-based paclitaxel}

The pharmacokinetic behavior of solvent-based paclitaxel in the elderly was examined in a study of patients with metastatic breast cancer, in which several parameters were compared between patients $\geq 70$ years of age and those $<70$ years of age. ${ }^{31}$ All patients received solvent-based paclitaxel as a 1-hour infusion at a dose of $80 \mathrm{mg} / \mathrm{m}^{2}$ ( $\geq 70$ years) or $100 \mathrm{mg} / \mathrm{m}^{2}$ ( $<70$ years) on days 1,8 , and 15 of a 28 -day cycle. Serial blood samples were collected immediately before the first administration and then at multiple time points up to 24 hours after the administration was completed. The pharmacokinetics of unbound paclitaxel and those of the solvent vehicle Cremophor EL (now renamed Kolliphor EL) were assessed. The authors reported that the clearance of unbound paclitaxel was considerably lower in the older group of patients versus the $<70$-year age group ( $124 \mathrm{vs} 247 \mathrm{~L} / \mathrm{h} / \mathrm{m}^{2} ; P=0.002$ ). Despite a lower dose, patients $\geq 70$ years of age also had a significantly slower clearance of Cremophor EL (150 vs $115 \mathrm{~mL} / \mathrm{h} / \mathrm{m}^{2}$; $P=0.04)$. The exact route of clearance for Cremophor EL is not well characterized; however, patients with diminished renal or hepatic function have not exhibited diminished 
clearance of Cremophor EL, suggesting that it is not primarily eliminated by the kidneys or liver. ${ }^{29,32-34}$ Interestingly, rates of neutropenia were the same between the two age groups in this study, perhaps due to increased paclitaxel exposure or decreased bone marrow reserve in older patients. Although the exact impact of this altered pharmacokinetic behavior on adverse events (AEs) is difficult to quantify, a relationship has been described between the duration that plasma paclitaxel concentration remains $\geq 0.05 \mu \mathrm{mol} / \mathrm{L}$ and the occurrence of neutropenia. ${ }^{35}$ The altered pharmacokinetics described suggests that issues of dosing and schedule may prove to be of great importance in elderly patients receiving solvent-based paclitaxel.

The authors of a pooled analysis of two trials conducted by the Cancer and Leukemia Group B (CALGB) sought to examine whether the efficacy of solvent-based paclitaxel treatment was correlated with age. ${ }^{36}$ Patients receiving both weekly and every-3-week schedules were pooled, and evaluations were carried out in different subgroups of patients based on age: $<55$ years $(n=470), 55-64$ years $(n=306)$, and $\geq 65$ years $(n=272)$. Notably, performance status did not differ among the three groups. Multivariate analyses found that age alone did not correlate with ORR, OS, or progression-free survival (PFS); however, performance status and receiving therapy in the first-line setting did significantly correlate with ORR, OS, and PFS. Although age did not appear to correlate with efficacy, age did correlate with some AEs, including grade $\geq 3$ neurotoxicity. The occurrence of grade $\geq 3$ leukopenia $(P=0.0099)$, granulocytopenia $(P=0.022)$, anorexia $(P=0.028)$, hyperbilirubinemia $(P=0.0035)$, and malaise $(P=0.0028)$ also significantly correlated with age. The authors concluded that solvent-based paclitaxel "is as effective in carefully selected older as in younger patients with metastatic breast cancer. The increased risk of neurotoxicity in elders is of concern and older patients should be closely monitored for this event."

A handful of smaller studies have prospectively examined solvent-based paclitaxel for metastatic breast cancer in elderly patient populations (Tables 1 and 2). ${ }^{37-39}$ The median ages of patients in these studies ranged from 74 to 77 years, all three included mostly fit elderly patients (more than $80 \%$ with a performance status of 0 or 1 ) with adequate liver

Table I Efficacy of taxanes in elderly patients

\begin{tabular}{|c|c|c|c|c|c|c|c|}
\hline & $\mathbf{n}$ & Treatment & Line of therapy & PS & $\begin{array}{l}\text { Age in years, } \\
\text { median }\end{array}$ & ORR (\%) & $\begin{array}{l}\text { OS in months } \\
\text { (median) }\end{array}$ \\
\hline \multicolumn{8}{|l|}{ sb-P } \\
\hline ten Tije et $a^{38}$ & 23 & sb-P 80 mg/m² qw 3/4 & First & $0-2$ & 77 & 38 & NR \\
\hline Del Mastro et $\mathrm{al}^{39}$ & 41 & sb-P 80 mg/m² qw $3 / 4$ & First & $0-2$ & 74 & 54 & 35.8 \\
\hline \multirow[t]{2}{*}{ Beuselinck et $\mathrm{a}^{37}$} & 28 & $\mathrm{sb}-\mathrm{P} 80 \mathrm{mg} / \mathrm{m}^{2} \mathrm{qw}$ & $\geq$ First & $0-2$ & $75-76^{a}$ & 50 & NR \\
\hline & & D $36 \mathrm{mg} / \mathrm{m}^{2} \mathrm{qw}$ & & & & 25 & \\
\hline Lichtman et $\mathrm{al}^{36, \mathrm{~b}}$ & 271 & sb-P 80 mg/m² qw; sb-P $175-250 \mathrm{mg} / \mathrm{m}^{2}$ q3w & First or second & $0-2$ & $\geq 65$ & $35 / 24^{c}$ & NR \\
\hline \multicolumn{8}{|l|}{ D } \\
\hline Hainsworth et $\mathrm{al}^{43}$ & 36 & D $36 \mathrm{mg} / \mathrm{m}^{2} \mathrm{qw} 6 / 8$ & First or second & $0-2$ & $74^{d}$ & 36 & 13 \\
\hline D'hondt et al ${ }^{44}$ & 37 & D $36 \mathrm{mg} / \mathrm{m}^{2} \mathrm{qw} 6 / 7 \rightarrow \mathrm{qw} 2 / 3$ or $\mathrm{qw} 3 / 4$ & $\geq$ First & $0-3$ & 63 & 30 & 6.5 \\
\hline Maisano et $\mathrm{al}^{45}$ & 21 & D $35 \mathrm{mg} / \mathrm{m}^{2}$ qw $6 / 8 \rightarrow \mathrm{qw} 3 / 4$ & First & $0-2$ & $\geq 70$ & 33 & NR \\
\hline Lorenzo et $\mathrm{al}^{46}$ & 28 & D $50-100 \mathrm{mg} / \mathrm{m}^{2} \mathrm{q} 3 \mathrm{w}$ or $\mathrm{q} 4 \mathrm{w}$ & First or second & $0-2$ & 72 & 50 & 26.6 \\
\hline Massacesi et $\mathrm{al}^{47}$ & 33 & $\begin{array}{l}\text { D } 25-30 \mathrm{mg} / \mathrm{m}^{2} \mathrm{qw}, 40-50 \mathrm{mg} / \mathrm{m}^{2} \mathrm{q} 2 \mathrm{w} \text {, or } \\
75-100 \mathrm{mg} / \mathrm{m}^{2} \mathrm{q} 3 \mathrm{w}\end{array}$ & $>$ First & $0->2$ & 70 & 24 & 16 \\
\hline Pivot et al $\left.\right|^{42, b}$ & & D $100 \mathrm{mg} / \mathrm{m}^{2} \mathrm{q} 3 \mathrm{w}$ & First & $0-1$ & & & NR \\
\hline & 38 & + placebo & & & 67 & 45 & \\
\hline & 41 & + bev $7.5 \mathrm{mg} / \mathrm{kg}$ & & & 69 & 37 & \\
\hline & 48 & + bev $15 \mathrm{mg} / \mathrm{kg}$ & & & 68 & 50 & \\
\hline \multicolumn{8}{|l|}{ nab-P } \\
\hline \multirow[t]{6}{*}{ Aapro et $\mathrm{a}^{50, \mathrm{~b}}$} & 30 & nab-P $260 \mathrm{mg} / \mathrm{m}^{2} \mathrm{q} 3 \mathrm{w}$ & $\geq$ First & $0-2$ & 70 & 27 & 17.6 \\
\hline & 32 & sb-P 175 mg/m² q3w & & & 69 & 19 & 12.8 \\
\hline & 9 & nab-P $300 \mathrm{mg} / \mathrm{m}^{2} \mathrm{q} 3 \mathrm{w}$ & First & $0-2$ & 67 & 22 & 19.9 \\
\hline & 14 & nab-P $100 \mathrm{mg} / \mathrm{m}^{2}$ qw $3 / 4$ & & & 69 & 64 & 21.7 \\
\hline & 10 & nab-P I 50 mg/m² qw $3 / 4$ & & & 67 & 60 & 20.7 \\
\hline & 19 & D $100 \mathrm{mg} / \mathrm{m}^{2} \mathrm{q} 3 \mathrm{w}$ & & & 69 & 32 & 21.2 \\
\hline
\end{tabular}

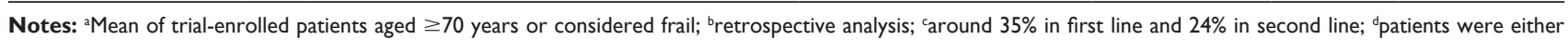
aged $>65$ years or considered poor candidates for combination chemotherapy.

Abbreviations: bev, bevacizumab; D, docetaxel; nab, nanoparticle albumin-bound; NR, not reported; ORR, overall response rate; OS, overall survival; P, paclitaxel; PS, performance status; q2w, every 2 weeks; q3w, every 3 weeks; q4w, every 4 weeks; qw, weekly; qw 2/3, the first 2 of 3 weeks; qw 3/4, the first 3 of 4 weeks; qw 6/7, the first 6 of 7 weeks; qw 6/8, the first 6 of 8 weeks; sb, solvent-based. 
Table 2 Safety of taxanes in elderly patients

\begin{tabular}{|c|c|c|c|c|c|}
\hline & \multirow[t]{2}{*}{$\mathbf{n}$} & \multirow[t]{2}{*}{ Treatment } & \multicolumn{3}{|c|}{ Grade $\geq 3$ adverse events (\%) } \\
\hline & & & Neutropenia & Fatigue & Sensory neuropathy \\
\hline \multicolumn{6}{|l|}{ sb-P } \\
\hline ten Tije et $\mathrm{al}^{38}$ & 26 & sb-P 80 mg/m² qw 3/4 & 12 & 4 & $4^{\mathrm{a}}$ \\
\hline Del Mastro et $\mathrm{al}^{39}$ & 46 & sb-P 80 mg/m² qw $3 / 4$ & 9 & 4 & 2 \\
\hline \multirow{2}{*}{ Beuselinck et $\mathrm{a}^{37}$} & $33^{\mathrm{b}}$ & $\mathrm{sb}-\mathrm{P} 80 \mathrm{mg} / \mathrm{m}^{2} \mathrm{qw}$ & 45 & 6 & 9 \\
\hline & $37^{\mathrm{b}}$ & D $36 \mathrm{mg} / \mathrm{m}^{2} \mathrm{qw}$ & 19 & 8 & 3 \\
\hline Lichtman et $\mathrm{a}^{36, \mathrm{c}}$ & 270 & sb-P 80 mg/m² qw; sb-P I75-250 mg/m² q3w & NR & $10^{\mathrm{d}}$ & 28 \\
\hline \multicolumn{6}{|c|}{$e_{0}$} \\
\hline Hainsworth et $\mathrm{a}^{43}$ & 41 & D 36 mg/m² qw $6 / 8$ & $2^{\mathrm{e}}$ & 20 & 0 \\
\hline D'hondt et al ${ }^{44}$ & 47 & D $36 \mathrm{mg} / \mathrm{m}^{2} \mathrm{qw} 6 / 7 \rightarrow \mathrm{qw} 2 / 3$ or $\mathrm{qw} 3 / 4$ & 21 & 0 & 0 \\
\hline Maisano et $\mathrm{al}^{45}$ & 21 & D $35 \mathrm{mg} / \mathrm{m}^{2}$ qw $6 / 8 \rightarrow \mathrm{qw} 3 / 4$ & 5 & $10^{f}$ & NR \\
\hline Lorenzo et $\mathrm{al}^{46}$ & 28 & D $50-100 \mathrm{mg} / \mathrm{m}^{2} \mathrm{q} 3-4 \mathrm{w}$ & 18 & $7^{f}$ & 4 \\
\hline Massacesi et al ${ }^{147}$ & 37 & $\begin{array}{l}\text { D } 25-30 \mathrm{mg} / \mathrm{m}^{2} \mathrm{qw}, 40-50 \mathrm{mg} / \mathrm{m}^{2} \mathrm{q} 2 \mathrm{w} \text {, } \\
\text { or } 75-100 \mathrm{mg} / \mathrm{m}^{2} \mathrm{q} 3 \mathrm{w}\end{array}$ & 14 & $22^{f}$ & 0 \\
\hline \multirow[t]{4}{*}{ Pivot et a $\left.\right|^{42, c}$} & & D $100 \mathrm{mg} / \mathrm{m}^{2} \mathrm{q} 3 \mathrm{w}$ & & NR & NR \\
\hline & 38 & + placebo & 19 & & \\
\hline & 41 & + bev $7.5 \mathrm{mg} / \mathrm{kg}$ & 27 & & \\
\hline & 48 & + bev $15 \mathrm{mg} / \mathrm{kg}$ & 33 & & \\
\hline \multicolumn{6}{|l|}{ nab-P } \\
\hline \multirow[t]{6}{*}{ Aapro et al $\left.\right|^{50, c}$} & 30 & nab-P $260 \mathrm{mg} / \mathrm{m}^{2} \mathrm{q} 3 \mathrm{w}$ & 33 & 10 & 17 \\
\hline & 32 & sb-P 175 mg/m² q3w & 66 & 6 & 0 \\
\hline & 9 & nab-P $300 \mathrm{mg} / \mathrm{m}^{2} \mathrm{q} 3 \mathrm{w}$ & 67 & 0 & 11 \\
\hline & 14 & nab-P 100 mg/m² qw $3 / 4$ & 36 & 14 & 21 \\
\hline & 10 & nab-P I 50 mg/m² qw 3/4 & 50 & 10 & 20 \\
\hline & 19 & D $100 \mathrm{mg} / \mathrm{m}^{2} \mathrm{q} 3 \mathrm{w}$ & 84 & 32 & 16 \\
\hline
\end{tabular}

Notes: ${ }^{a}$ Reported as neuropathy; ${ }^{b}$ percentages based on the entire elderly/frail population (elderly-specific data not given); ${ }^{c}$ retrospective analysis; ${ }^{d}$ reported as malaise; ereported as neutropenia/fever; ' reported as asthenia.

Abbreviations: bev, bevacizumab; D, docetaxel; nab, nanoparticle albumin-bound; NR, not reported; P, paclitaxel; q2w, every 2 weeks; q3w, every 3 weeks; qw, weekly; qw 2/3, the first 2 of 3 weeks; qw 3/4, the first 3 of 4 weeks; qw 6/7, the first 6 of 7 weeks; qw 6/8, the first 6 of 8 weeks; sb, solvent-based.

and kidney function, and most patients received the given regimen as first-line therapy for advanced disease. ORRs ranged from $24 \%$ to $54 \%$. The most common grade $\geq 3$ AEs in these studies were neutropenia $(9 \%-45 \%)$ and sensory neuropathy $(2 \%-28 \%)$.

In the data described above on elderly breast cancer patients receiving solvent-based paclitaxel, age did not appear to correlate with efficacy. However, subsequent studies suggested that age may be correlated with some pharmacokinetic parameters (total body clearance and volume of distribution of unbound paclitaxel) and the occurrence of some grade $\geq 3$ AEs, including neurotoxicity, anorexia, and some hematologic toxicities. ${ }^{36,40}$ In addition, the rates of grade $1 / 2$ peripheral or sensory neuropathy in these studies of solvent-based paclitaxel for elderly patients ranged from $35 \%$ to $48 \%$. $^{37-39}$

A report by the Belgian Society of Medical Oncology compared weekly solvent-based paclitaxel $80 \mathrm{mg} / \mathrm{m}^{2}$ with weekly docetaxel $36 \mathrm{mg} / \mathrm{m}^{2}$ in a Phase II trial $(\mathrm{N}=70)$ of older or frail patients with metastatic breast cancer. ${ }^{37}$ Of the 70 patients enrolled, 28 were aged $\geq 70$ years and 42 were aged $<70$ years. Frailty was defined as expected hematologic problems from past experience with chemotherapy or radiation and/or low starting neutrophils or platelets, liver function abnormalities, or grade 2 AEs during prior therapy with a taxane on an every-3-week schedule. The ORR for the entire population was $43 \%$. Among patients $\geq 70$ years of age, the ORRs for the pooled group, the solvent-based paclitaxel group, and the docetaxel group were $36 \%, 50 \%$, and $25 \%$, respectively (Table 1). Univariate analysis of the efficacy results adjusted for age showed that age was not a prognostic factor for ORR. Tolerability data for patients $\geq 70$ years of age were not given. The authors cautioned against drawing any conclusions with respect to the comparison of the two treatment regimens since the trial was not designed or powered for a statistically valid comparison. In addition, the patients in the solvent-based paclitaxel arm received more cycles of treatment compared with those in the docetaxel arm (median 11.0 [maximum 32] vs median 8.0 [maximum 22], respectively), potentially affecting the rates of AEs reported.

\section{Docetaxel}

A prospective trial of single-agent docetaxel in patients with solid tumors examined pharmacokinetics in those 
aged $\geq 65$ years versus those aged $<65$ years ( $n=20$ for each group). ${ }^{41}$ All patients received docetaxel $75 \mathrm{mg} / \mathrm{m}^{2}$ as a 1 -hour infusion every 3 weeks. No differences in pharmacokinetics were observed between the two groups in terms of docetaxel clearance $(30.1 \mathrm{~L} / \mathrm{h}$ for the elderly group vs $30.0 \mathrm{~L} / \mathrm{h}$ for the younger group) or drug exposure (6.01 vs $5.69 \mu \mathrm{g} / \mathrm{mL} \cdot \mathrm{h}$, respectively). However, the older group had a numerically higher rate of grade 4 neutropenia ( $65 \%$ vs $30 \% ; P=0.06$ ) as well as febrile neutropenia ( $16 \%$ vs $0 \%)$. A model generated based on the data from the younger patients suggested that the elderly patients may be more sensitive to docetaxel.

Tables 1 and 2 include clinical data for elderly patients who received docetaxel for the treatment of metastatic breast cancer. The study by Pivot et $\mathrm{al}^{42}$ was a retrospective subanalysis of the AVADO trial, which tested docetaxel $100 \mathrm{mg} / \mathrm{m}^{2}$ with or without bevacizumab (7.5 or $15 \mathrm{mg} / \mathrm{kg}$ ) every 3 weeks for patients with metastatic breast cancer. The primary endpoint of the study was PFS, and all patients had an Eastern Cooperative Oncology Group performance status of 0 or 1 . In elderly patients (defined as aged $\geq 65$ years; $\mathrm{n}=127$ ), both bevacizumab-containing groups produced longer median PFS values versus the placebo group, similar to what was observed in the intention-to-treat (ITT) population; however, the differences did not reach statistical significance (for the $7.5 \mathrm{mg} / \mathrm{kg}$ bevacizumab group vs placebo, $9.0 \mathrm{vs}$ 7.6 months, HR $=0.76, P=0.35$; for the $15 \mathrm{mg} / \mathrm{kg}$ bevacizumab group vs placebo, 10.3 vs 7.6 months, HR $=0.63$, $P=0.07$ ). ORRs were $45 \%, 37 \%$, and $50 \%$ in the placebo, bevacizumab $7.5 \mathrm{mg} / \mathrm{kg}$, and bevacizumab $15 \mathrm{mg} / \mathrm{kg}$ groups, respectively (no comparisons reached statistical significance). In the elderly population, the incidence rates of any grade $\geq 3$ AEs were $76 \%, 88 \%$, and $88 \%$ in the placebo, bevacizumab $7.5 \mathrm{mg} / \mathrm{kg}$, and bevacizumab $15 \mathrm{mg} / \mathrm{kg}$ groups, respectively. The authors concluded that efficacy in the elderly population was similar to that in the ITT population and that no unexpected safety signals were observed in elderly patients. However, the rate of AE-related deaths in the elderly population was higher for patients who received bevacizumab than for patients who received placebo ( $6 \% \mathrm{vs}$ $3 \% ; P$-value not reported). In the overall safety population, the rates of AE-related deaths were 3\% for the bevacizumab groups and $2 \%$ for the placebo group.

A number of prospective studies on docetaxel for the treatment of elderly patients with metastatic breast cancer have been conducted (Tables 1 and 2) ${ }^{43-47}$ As in studies of solvent-based paclitaxel, most of the patients in these trials had a performance status of $0-2$, and most were treated in the first- or second-line settings. The median ages ranged from
63 to 74 years. In approximately half of the docetaxel trials, a weekly dosing schedule was used; the other half used every 2-, 3-, or 4-week schedules (Tables 1 and 2). ${ }^{37,43-47}$ The ORRs were $24 \%-50 \%$, demonstrating efficacy in these patients, and median OS values were 6.5-26.6 months. The most common grade $\geq 3$ toxicities in these docetaxel studies were fatigue $(0 \%-22 \%)$ and neutropenia ( $2 \%-33 \%)$. Grade $\geq 3$ peripheral neuropathy was not common $(<5 \%)$.

The formulation of nab-paclitaxel does not include solvents, leading to possible pharmacokinetic advantages over solvent-based formulations. A pharmacokinetic study $(\mathrm{N}=17$; median age 65 years) in a general population of patients with solid tumors found that nab-paclitaxel $260 \mathrm{mg} / \mathrm{m}^{2}$, given as a 30-minute infusion, showed faster clearance of total drug versus solvent-based paclitaxel $175 \mathrm{mg} / \mathrm{m}^{2}$, given as a 3-hour infusion $\left(13.2 \mathrm{vs} 8.9 \mathrm{~L} / \mathrm{h} / \mathrm{m}^{2} ; P=0.00002\right){ }^{48}$ In a study that evaluated pharmacokinetics of nab-paclitaxel in an exclusively elderly population, Hurria et $\mathrm{al}^{49}$ reported the results of a study ( $\mathrm{N}=39$; mean age 60 years) in which they examined the pharmacokinetics of nab-paclitaxel $100 \mathrm{mg} / \mathrm{m}^{2}$ in the first 3 of 4 weeks in patients with metastatic breast cancer as a function of age and other factors. No significant associations were reported between age and any pharmacokinetic parameters, although there was a borderline significant association between increasing age and increasing total drug exposure (area under the curve; $P=0.055$ ).

\section{nab-paclitaxel}

Although no prospective studies have been conducted to evaluate the clinical benefit of nab-paclitaxel in elderly patients with metastatic breast cancer, a retrospective analysis examined efficacy and safety in older patients in a Phase III trial and a large, randomized Phase II trial of patients with metastatic breast cancer (Tables 1 and 2) ${ }^{30,50,51}$ The Phase III trial (mean age 53 years) showed greater efficacy for nab-paclitaxel $260 \mathrm{mg} / \mathrm{m}^{2}$ every 3 weeks versus solvent-based paclitaxel $175 \mathrm{mg} / \mathrm{m}^{2}$ every 3 weeks in patients receiving $\geq$ first-line treatment in terms of a higher ORR ( $33 \%$ vs $19 \% ; P=0.001)$ and a longer time to progression ( 23.0 vs 16.9 weeks; $P=0.006) .{ }^{30}$ The Phase II trial (mean age 52-55 years) compared three different regimens of nab-paclitaxel $\left(300 \mathrm{mg} / \mathrm{m}^{2}\right.$ every 3 weeks, $100 \mathrm{mg} / \mathrm{m}^{2}$ the first 3 of 4 weeks, and $150 \mathrm{mg} / \mathrm{m}^{2}$ the first 3 of 4 weeks) and docetaxel $100 \mathrm{mg} / \mathrm{m}^{2}$ every 3 weeks. ${ }^{51}$ The investigator-assessed ORRs for the ITT populations were $46 \%, 63 \%, 74 \%$, and $39 \%$, respectively, and the median values for PFS by investigator assessment were 10.9, 7.5, 14.6, and 7.8 months, respectively. The analysis of the elderly in these two trials included a total of 114 patients with a median age 
of 69 years. ${ }^{50}$ Among patients aged $\geq 65$ years in the Phase III trial, ORR was higher for nab-paclitaxel versus solventbased paclitaxel ( $27 \%$ vs $19 \%)$, and both median PFS (5.6 vs 3.5 months) and OS (17.6 vs 12.8 months) were longer for nab-paclitaxel versus solvent-based paclitaxel. In the Phase II study, the ORRs were $22 \%, 64 \%, 60 \%$, and $32 \%$ in patients receiving nab-paclitaxel $300 \mathrm{mg} / \mathrm{m}^{2}$, nab-paclitaxel $100 \mathrm{mg} / \mathrm{m}^{2}$ the first 3 of 4 weeks, nab-paclitaxel $150 \mathrm{mg} / \mathrm{m}^{2}$ the first 3 of 4 weeks, and docetaxel, respectively. Median PFS values were 13.8, 9.2, 18.9, and 8.5 months, and median OS values were 19.9, 21.7, 20.7, and 21.2 months, respectively. In general, the safety signals observed in the elderly patients in this analysis were similar to those of the ITT populations. The authors concluded that among elderly patients, weekly nab-paclitaxel was safe and more efficacious compared with the every-3-week schedule of nab-paclitaxel or the solventbased taxanes.

\section{Discussion}

Although overtreatment is a concern in older women with breast cancer, elderly patients have generally been underrepresented in clinical trials; as a result, they are often undertreated in the absence of consensus treatment guidelines. ${ }^{3,4}$ However, the literature suggests that at least some elderly patients derive similar benefits from cancer therapy as their younger counterparts. ${ }^{17}$ It seems that functional status of patients plays a more important role than physiological age in determining which kinds of therapies are appropriate. ${ }^{36}$ Although there are many physiological and clinical changes and challenges that may occur as patients age, a number of geriatric assessment tools are available to guide physicians in their treatment decision-making process. ${ }^{4,52-56}$ In trials that included a functional and comorbidity assessment, age did not significantly correlate with toxicity. The treating physician must also ensure that therapy does not directly diminish functional status, both for the patient's long-term well-being and for the impact such an effect would have on the patient's ability to be an ideal candidate for future lines of therapy.

SIOG guidelines state that weekly taxanes are among the preferred options for elderly patients in whom chemotherapy is indicated. ${ }^{4}$ Specifically, elderly patients with metastatic breast cancer may be candidates for chemotherapy, including taxanes, if they have disease that is hormone receptor negative, HR+ but refractory to endocrine therapy, or HR+ but rapidly progressing (such cases might call for chemotherapy plus endocrine therapy). Elderly patients with HER2+ disease may receive HER2-directed therapy plus chemotherapy, such as a taxane (single-agent trastuzumab may also be reasonable). ${ }^{4}$ HER2-directed therapy plus endocrine therapy is an option for metastatic breast cancer that is HER2+ and HR+ in patients for whom chemotherapy is contraindicated or for those without life-threatening disease. ${ }^{4}$

Multiple attempts have been made to modify the formulation of the currently available taxanes to maintain efficacy and improve tolerability. ${ }^{57-59}$ However, to date, nab-paclitaxel is the only formulation that has succeeded in this strategy in terms of receiving US Food and Drug Administration's approval for the treatment of metastatic breast cancer. ${ }^{24}$

Treating elderly patients with taxanes requires consideration of some specific challenges. Rates of peripheral neuropathy and diabetes increase with age ${ }^{60-63}$ Furthermore, many patients with diabetes develop a form of chronic painful peripheral neuropathy, ${ }^{64}$ so oncologists must be particularly conscious of preexisting neuropathy and diabetes when considering taxanes for elderly patients with metastatic breast cancer. Another concern for patients, especially those with diabetes, is that steroid pretreatment for chemotherapy - a requirement for solvent-based paclitaxel and docetaxel may cause fluctuations in blood sugar. ${ }^{21,23,65}$ Concerns over solvent-related hypersensitivity and the need for premedication are not applicable to nab-paclitaxel, because its administration does not require solvents. ${ }^{24}$ This advantage extends not only to elderly patients with metastatic breast cancer but also to patients with non-small-cell lung cancer or pancreatic cancer. ${ }^{24}$ In light of the foregoing challenges, careful consideration of patient and disease factors is required for physicians to take advantage of the demonstrated activity of taxanes. Future studies may lead to refinements in patient selection and dosing optimization to tailor taxane treatments to elderly patients with breast cancer.

\section{Conclusion}

Weekly single-agent taxanes are among the regimens recommended by the NCCN for the treatment of metastatic breast cancer (not specific to any age group), and guidelines by the SIOG state that weekly taxanes are an appropriate option for older patients. ${ }^{4} 18$ Age alone does not appear to warrant a mandatory dose reduction, and the weekly regimen that demonstrates reduced hematologic toxicity and comparable efficacy seems most reasonable. While solvent-based paclitaxel and docetaxel are viable options in these patients, ${ }^{36-39,42-47}$ a retrospective analysis suggests that the nonsolvent-based taxane nab-paclitaxel may offer a comparable or better therapeutic index,${ }^{50}$ perhaps as a result of a lesser impact of age on the pharmacokinetics of the drug within the body. ${ }^{31,48,49}$ For such findings to guide treatment 
decisions regarding older patients with breast cancer, a large prospective study in elderly patients would be necessary to confirm these data.

\section{Acknowledgments}

Medical writing assistance was provided by John McGuire, $\mathrm{PhD}$, MediTech Media, funded by Celgene Corporation. The author is fully responsible for content and editorial decisions for this manuscript.

\section{Disclosure}

The author reports no conflicts of interest in this work.

\section{References}

1. Howlader N, Noone AM, Krapcho M, et al. SEER Cancer Statistics Review, 1975-2011. Bethesda, MD: National Cancer Institute; 2014.

2. Smith BD, Jiang J, McLaughlin SS, et al. Improvement in breast cancer outcomes over time: are older women missing out? J Clin Oncol. 2011;29(35):4647-4653.

3. Bouchardy C, Rapiti E, Fioretta G, et al. Undertreatment strongly decreases prognosis of breast cancer in elderly women. J Clin Oncol. 2003;21(19):3580-3587.

4. Biganzoli L, Wildiers H, Oakman C, et al. Management of elderly patients with breast cancer: updated recommendations of the International Society of Geriatric Oncology (SIOG) and European Society of Breast Cancer Specialists (EUSOMA). Lancet Oncol. 2012;13(4):e148-e160.

5. Hurria A, Lichtman SM. Clinical pharmacology of cancer therapies in older adults. Br J Cancer. 2008;98(3):517-522.

6. Vestal RE. Aging and pharmacology. Cancer. 1997;80(7):1302-1310.

7. Fehrman-Ekholm I, Skeppholm L. Renal function in the elderly $(>70$ years old) measured by means of iohexol clearance, serum creatinine, serum urea and estimated clearance. Scand J Urol Nephrol. 2004;38(1):73-77.

8. Borkowski JM, Duerr M, Donehower RC, et al. Relation between age and clearance rate of nine investigational anticancer drugs from phase I pharmacokinetic data. Cancer Chemother Pharmacol. 1994; 33(6):493-496.

9. Nixon AJ, Neuberg D, Hayes DF, et al. Relationship of patient age to pathologic features of the tumor and prognosis for patients with stage I or II breast cancer. J Clin Oncol. 1994;12(5):888-894.

10. Diab SG, Elledge RM, Clark GM. Tumor characteristics and clinical outcome of elderly women with breast cancer. J Natl Cancer Inst. 2000; 92(7):550-556.

11. Ring A, Sestak I, Baum M, et al. Influence of comorbidities and age on risk of death without recurrence: a retrospective analysis of the arimidex, tamoxifen alone or in combination trial. J Clin Oncol. 2011; 29(32):4266-4272.

12. Hurria A. Embracing the complexity of comorbidity. $J$ Clin Oncol. 2011;29(32):4217-4218.

13. Von Hoff DD, Rozencweig M, Layard M, Slavik M, Muggia FM. Daunomycin-induced cardiotoxicity in children and adults. A review of 110 cases. Am J Med. 1977;62(2):200-208.

14. Von Hoff DD, Layard MW, Basa P, et al. Risk factors for doxorubicin-induced congestive heart failure. Ann Intern Med. 1979;91(5): 710-717.

15. Onitilo AA, Engel JM, Stankowski RV. Cardiovascular toxicity associated with adjuvant trastuzumab therapy: prevalence, patient characteristics, and risk factors. Ther Adv Drug Saf. 2014;5(4):154-166.

16. Delafuente JC. Understanding and preventing drug interactions in elderly patients. Crit Rev Oncol Hematol. 2003;48(2):133-143.
17. Christman K, Muss HB, Case LD, Stanley V. Chemotherapy of metastatic breast cancer in the elderly. The Piedmont Oncology Association experience [see comment]. JAMA. 1992;268(1):57-62.

18. The National Comprehensive Cancer Network. National Comprehensive Cancer Network Clinical Practice Guidelines in Oncology. Breast Cancer. Version 2.2015, 2015

19. Nahta R, Hung MC, Esteva FJ. The HER-2-targeting antibodies trastuzumab and pertuzumab synergistically inhibit the survival of breast cancer cells. Cancer Res. 2004;64(7):2343-2346.

20. Xeloda ${ }^{\circledR}$ (capecitabine) [package insert]. South San Francisco, CA: Genentech; 2011.

21. Taxotere ${ }^{\circledR}$ (docetaxel) Injection Concentrate [package insert]. Bridgewater, NJ: Sanofi-aventis US LLC; 2010.

22. Adriamycin ${ }^{\circledR}$ (doxorubicin $\mathrm{HCl}$ ) for Injection, USP [package insert]. Bedford, OH: Bedford Laboratories; 2012.

23. Taxol ${ }^{\circledR}$ (paclitaxel) [package insert]. Princeton, NJ: Bristol-Myers Squibb Company; 2011

24. Abraxane ${ }^{\circledR}$ for Injectable Suspension (paclitaxel protein-bound particles for injectable suspension) (albumin-bound) [package insert]. Summit, NJ: Celegene Corporation; 2014.

25. Schiff PB, Fant J, Horwitz SB. Promotion of microtubule assembly in vitro by taxol. Nature. 1979;277(5698):665-667.

26. Schiff PB, Horwitz SB. Taxol stabilizes microtubules in mouse fibroblast cells. Proc Natl Acad Sci U S A. 1980;77(3):1561-1565.

27. Wani MC, Taylor HL, Wall ME, Coggon P, McPhail AT. Plant antitumor agents. VI. The isolation and structure of taxol, a novel antileukemic and antitumor agent from taxus brevifolia. J Am Chem Soc. 1971; 93(9):2325-2327.

28. O'Shaughnessy J. Extending survival with chemotherapy in metastatic breast cancer. Oncologist. 2005;10(Suppl 3):20-29.

29. ten Tije AJ, Verweij J, Loos WJ, Sparreboom A. Pharmacological effects of formulation vehicles: implications for cancer chemotherapy. Clin Pharmacokinet. 2003;42(7):665-685.

30. Gradishar WJ, Tjulandin S, Davidson N, et al. Phase III trial of nanoparticle albumin-bound paclitaxel compared with polyethylated castor oil-based paclitaxel in women with breast cancer. J Clin Oncol. 2005; 23(31):7794-7803.

31. Smorenburg CH, ten Tije AJ, Verweij J, et al. Altered clearance of unbound paclitaxel in elderly patients with metastatic breast cancer. Eur J Cancer. 2003;39(2):196-202.

32. van Zuylen L, Verweij J, Sparreboom A. Role of formulation vehicles in taxane pharmacology. Invest New Drugs. 2001;19(2):125-141.

33. Gelderblom H, Verweij J, Brouwer E, et al. Disposition of [G-(3)H] paclitaxel and cremophor EL in a patient with severely impaired renal function. Drug Metab Dispos. 1999;27(11):1300-1305.

34. Panday VR, Huizing MT, Willemse PH, et al. Hepatic metabolism of paclitaxel and its impact in patients with altered hepatic function. Semin Oncol. 1997;24(4 Suppl 11):S11-34-S11-38.

35. Gianni L, Kearns CM, Giani A, et al. Nonlinear pharmacokinetics and metabolism of paclitaxel and its pharmacokinetic/pharmacodynamic relationships in humans. J Clin Oncol. 1995;13(1):180-190.

36. Lichtman SM, Hurria A, Cirrincione CT, et al. Paclitaxel efficacy and toxicity in older women with metastatic breast cancer: combined analysis of CALGB 9342 and 9840. Ann Oncol. 2012;23(3):632-638.

37. Beuselinck B, Wildiers H, Wynendaele W, Dirix L, Kains JP, Paridaens R. Weekly paclitaxel versus weekly docetaxel in elderly or frail patients with metastatic breast carcinoma: a randomized phase-II study of the Belgian Society of Medical Oncology. Crit Rev Oncol Hematol. 2010;75(1):70-77.

38. ten Tije AJ, Smorenburg CH, Seynaeve C, et al. Weekly paclitaxel as first-line chemotherapy for elderly patients with metastatic breast cancer. A multicentre phase II trial. Eur J Cancer. 2004;40(3):352-357.

39. Del Mastro L, Perrone F, Repetto L, et al. Weekly paclitaxel as firstline chemotherapy in elderly advanced breast cancer patients: a phase II study of the Gruppo Italiano di Oncologia Geriatrica (GIOGer). Ann Oncol. 2005;16(2):253-258. 
40. Smorenburg $\mathrm{CH}$, ten Tije AJ. Reply to "weekly paclitaxel as firstline chemotherapy in elderly advanced breast cancer patients: a phase II study of the Gruppo Italiano di Oncologia Geriatrica (GIOGer)" by L. del Mastro et al. (Ann Oncol 2005;16:253-258). Ann Oncol. 2005;16(12):1979; author reply 1979-1980.

41. ten Tije AJ, Verweij J, Carducci MA, et al. Prospective evaluation of the pharmacokinetics and toxicity profile of docetaxel in the elderly. J Clin Oncol. 2005;23(6):1070-1077.

42. Pivot X, Schneeweiss A, Verma S, et al. Efficacy and safety of bevacizumab in combination with docetaxel for the first-line treatment of elderly patients with locally recurrent or metastatic breast cancer: results from AVADO. Eur J Cancer. 2011;47(16):2387-2395.

43. Hainsworth JD, Burris HA 3rd, Yardley DA, et al. Weekly docetaxel in the treatment of elderly patients with advanced breast cancer: a Minnie Pearl Cancer Research Network phase II trial. J Clin Oncol. 2001; 19(15):3500-3505.

44. D'hondt R, Paridaens R, Wildiers H, et al. Safety and efficacy of weekly docetaxel in frail and/or elderly patients with metastatic breast cancer: a phase II study. Anticancer Drugs. 2004;15(4):341-346.

45. Maisano R, Mare M, Caristi N, et al. A modified weekly docetaxel schedule as first-line chemotherapy in elderly metastatic breast cancer: a safety study. J Chemother. 2005;17(2):242-246.

46. Lorenzo I, Constenla M, Palacios P, et al. Docetaxel as single-agent treatment in elderly patients with advanced breast cancer. Clin Drug Investig. 2005;25(4):249-256.

47. Massacesi C, Marcucci F, Boccetti T, et al. Low dose-intensity docetaxel in the treatment of pre-treated elderly patients with metastatic breast cancer. J Exp Clin Cancer Res. 2005;24(1):43-48.

48. Gardner ER, Dahut WL, Scripture CD, et al. Randomized crossover pharmacokinetic study of solvent-based paclitaxel and nab-paclitaxel. Clin Cancer Res. 2008;14(13):4200-4205.

49. Hurria A, Blanchard MS, Synold TW, et al. Age-related changes in nanoparticle albumin-bound paclitaxel pharmacokinetics and pharmacodynamics: influence of chronological versus functional age. Oncologist. 2015;20(1):37-44.

50. Aapro M, Tjulandin S, Bhar P, Gradishar W. Weekly nab-paclitaxel is safe and effective in $>/=65$ years old patients with metastatic breast cancer: a post-hoc analysis. Breast. 2011;20(5):468-474.

51. Gradishar WJ, Krasnojon D, Cheporov S, et al. Significantly longer progression-free survival with nab-paclitaxel compared with docetaxel as first-line therapy for metastatic breast cancer. J Clin Oncol. 2009; 27(22):3611-3619.
52. Pallis AG, Fortpied C, Wedding U, et al. EORTC elderly task force position paper: approach to the older cancer patient. Eur $J$ Cancer. 2010;46(9):1502-1513.

53. Pallis AG, Wedding U, Lacombe D, Soubeyran P, Wildiers H. Questionnaires and instruments for a multidimensional assessment of the older cancer patient: what clinicians need to know? Eur J Cancer. 2010;46(6):1019-1025.

54. PACE participants; Audisio RA, Pope D, et al. Shall we operate? Preoperative assessment in elderly cancer patients (PACE) can help. A SIOG surgical task force prospective study. Crit Rev Oncol Hematol. 2008;65(2):156-163.

55. Hurria A, Cirrincione CT, Muss HB, et al. Implementing a geriatric assessment in cooperative group clinical cancer trials: CALGB 360401. J Clin Oncol. 2011;29(10):1290-1296.

56. Soubeyran P, Bellera C, Goyard J, et al. Validation of the G8 screening tool in geriatric oncology: the ONCODAGE project. J Clin Oncol (Meeting Abstracts). 2011;29(15 Suppl):Abstract 9001.

57. Singla AK, Garg A, Aggarwal D. Paclitaxel and its formulations. Int J Pharm. 2002;235(1-2):179-192.

58. Luo C, Wang Y, Chen Q, et al. Advances of paclitaxel formulations based on nanosystem delivery technology. Mini Rev Med Chem. 2012; 12(5):434-444.

59. Engels FK, Mathot RA, Verweij J. Alternative drug formulations of docetaxel: a review. Anticancer Drugs. 2007;18(2):95-103.

60. Sehl M, Sawhney R, Naeim A. Physiologic aspects of aging: impact on cancer management and decision making, part II. Cancer J. 2005; 11(6):461-473.

61. Balducci L, Mowry K. Pharmacology and organ toxicity of chemotherapy in older patients. Oncology (Williston Park). 1992;6(2 Supp1): 62-68.

62. Davis MP, Srivastava M. Demographics, assessment and management of pain in the elderly. Drugs Aging. 2003;20(1):23-57.

63. Yancik R, Wesley MN, Ries LA, Havlik RJ, Edwards BK, Yates JW. Effect of age and comorbidity in postmenopausal breast cancer patients aged 55 years and older. JAMA. 2001;285(7):885-892.

64. Daousi C, MacFarlane IA, Woodward A, Nurmikko TJ, Bundred PE, Benbow SJ. Chronic painful peripheral neuropathy in an urban community: a controlled comparison of people with and without diabetes. Diabet Med. 2004;21(9):976-982.

65. Hickish T, Astras G, Thomas P, et al. Glucose intolerance during adjuvant chemotherapy for breast cancer. J Natl Cancer Inst. 2009; 101(7):537.
Breast Cancer: Targets and Therapy

\section{Publish your work in this journal}

Breast Cancer: Targets and Therapy is an international, peerreviewed open access journal focusing on breast cancer research, identification of therapeutic targets and the optimal use of preventative and integrated treatment interventions to achieve improved outcomes, enhanced survival and quality of life for the cancer patient.

\section{Dovepress}

View the full aims and scopes of this journal here. The manuscript management system is completely online and includes a very quick and fair peer-review system, which is all easy to use. Visit http:// www.dovepress.com/testimonials.php to read real quotes from published authors. 